\title{
Microhabitat Use and Vertical Habitat Partitioning of Juvenile Atlantic (Gadus morhua) and Greenland (Gadus ogac) Cod in Coastal Newfoundland
}

\author{
D. Craig Knickle* and George A. Rose
}

Centre for Fisheries Ecosystems Research, Fisheries and Marine Institute of Memorial University of Newfoundland, P.O. Box 4920, St. John's, NL, AlC 5R3, Canada

\begin{abstract}
Twenty co-occurring juvenile gadids (10 Gadus ogac and 10 Gadus morhua) were surgically implanted with ultrasonic transmitters with depth sensors and continuously monitored for up to 23 days in the summers of 2009 and 2010 to test fine-scale habitat use and vertical distribution overlap in coastal Newfoundland ( $>18700$ positional fixes). A habitat map with 8 substrate and 3 slope classes $\left(\right.$ low $\left(<5^{\circ}\right)$, moderate $\left(5-10^{\circ}\right)$, and high $\left(>10^{\circ}\right)$ ) was generated from acoustic data and coincident video data using seabed mapping software (QTC). Fish locations were integrated with a habitat map to assess and quantify habitat preference. Both species avoided fine gravel/sand substrates with little vegetation and selected for large particle (cobble and boulder) substrates with moderate or dense vegetation, and spent the majority of time in $<10 \mathrm{~m}$ of water. Nevertheless, species differences in habitat use were evident. G. ogac typically remained in close proximity to the seafloor whereas $G$. morhua was often distributed more pelagically and showed greater variation in vertical distribution. Habitat use and vertical distribution patterns were consistent across the diel period. Our results suggest that despite high overlap in habitat use, G. morhua and G. ogac often segregate vertically in the water column, which may reduce competitive interference. We suggest that these patterns are related to differences in diet.
\end{abstract}

Keywords: Cod, Gadus, habitat mapping, habitat utilization, niche partitioning, telemetry.

\section{INTRODUCTION}

Divergent habitat selection is a common attribute of closely related species that may reduce competition and promote coexistence [1-4]. Atlantic cod (Gadus morhua) and Greenland cod (Gadus ogac) are two congeneric species of gadids that co-occur as juveniles in coastal areas of Newfoundland and Labrador and more northern areas to Greenland $[5,6]$. It has been suggested that competition for resources between the two species is likely [7], however few studies on their interactions exist.

Recent studies suggest that sympatry of these species is facilitated primarily through partitioning of food resources, with G. morhua pursuing more pelagic prey [8] and to a lesser extent by differences in activity patterns [9]. However, microhabitat partitioning could also be an enabler of sympatry but has not been studied in these species. Competition for habitat can negatively impact fitness components such as growth and survival by forcing individuals to use habitats that offer less protection from predators or poorer foraging opportunities [10].

Despite being an important commercial species for 500 years [6], habitat associations of age 2-4 juvenile G. morhua in coastal Newfoundland remain uncertain. Several studies have shown juveniles preferred areas with macroalgae and/or coarse substrates and generally avoided fine substrates

*Address correspondence to this author at the Centre for Fisheries Ecosystems Research, Fisheries and Marine Institute of Memorial University of Newfoundland, P.O. Box 4920, St. John's, NL, A1C 5R3, Canada; Tel: 709-778-0562; Fax: 709-778-0669;

E-mail: craig.knickle@mi.mun.ca
[11-16]. Other studies reported that juveniles did not associate with macroalgae $[13,17]$ or typically occurred over sand [18]. No studies of habitat utilization by G. ogac have been reported from Newfoundland waters. In other regions, adult and juvenile $G$. ogac occupied shallow (2-5 m) coastal waters characterized by belts of eelgrass (Zostera marina) during summer in southern Hudson's Bay [19] and were observed in slightly deeper water $(<35 \mathrm{~m})$ more northerly [20].

In this study, we combined acoustic habitat mapping with radio-acoustic positioning of individual fish to compare finescale habitat utilization of co-occurring juvenile $G$. morhua and $G$. ogac in coastal Newfoundland. The purpose of the study was to determine the degree of overlap or separation in habitat use in order to help explain the co-existence of these ecologically similar species. Based on previous studies, we hypothesized that both species would select for similar habitat types and show a preference for coarse substrates and areas with macroalgae while avoiding open areas and fine substrates. We also hypothesized that G. morhua but not G. ogac would show a preference for areas of high bathymetric relief and that $G$. ogac would be more benthically distributed as compared to more pelagic distributions of G. morhua.

\section{MATERIALS AND METHODS}

\section{Study Area}

The study was carried out in a small cove located in Smith Sound on the western side of Trinity Bay, Newfoundland, Canada $\left(48^{\circ} 10^{\prime} \mathrm{N}, 53^{\circ} 44^{\prime} \mathrm{W}\right)$ (Fig. 1). Water depth at the site ranged from $<1 \mathrm{~m}$ to $>50 \mathrm{~m}$. The site comprised of various habitat types ranging from flat, open areas to 


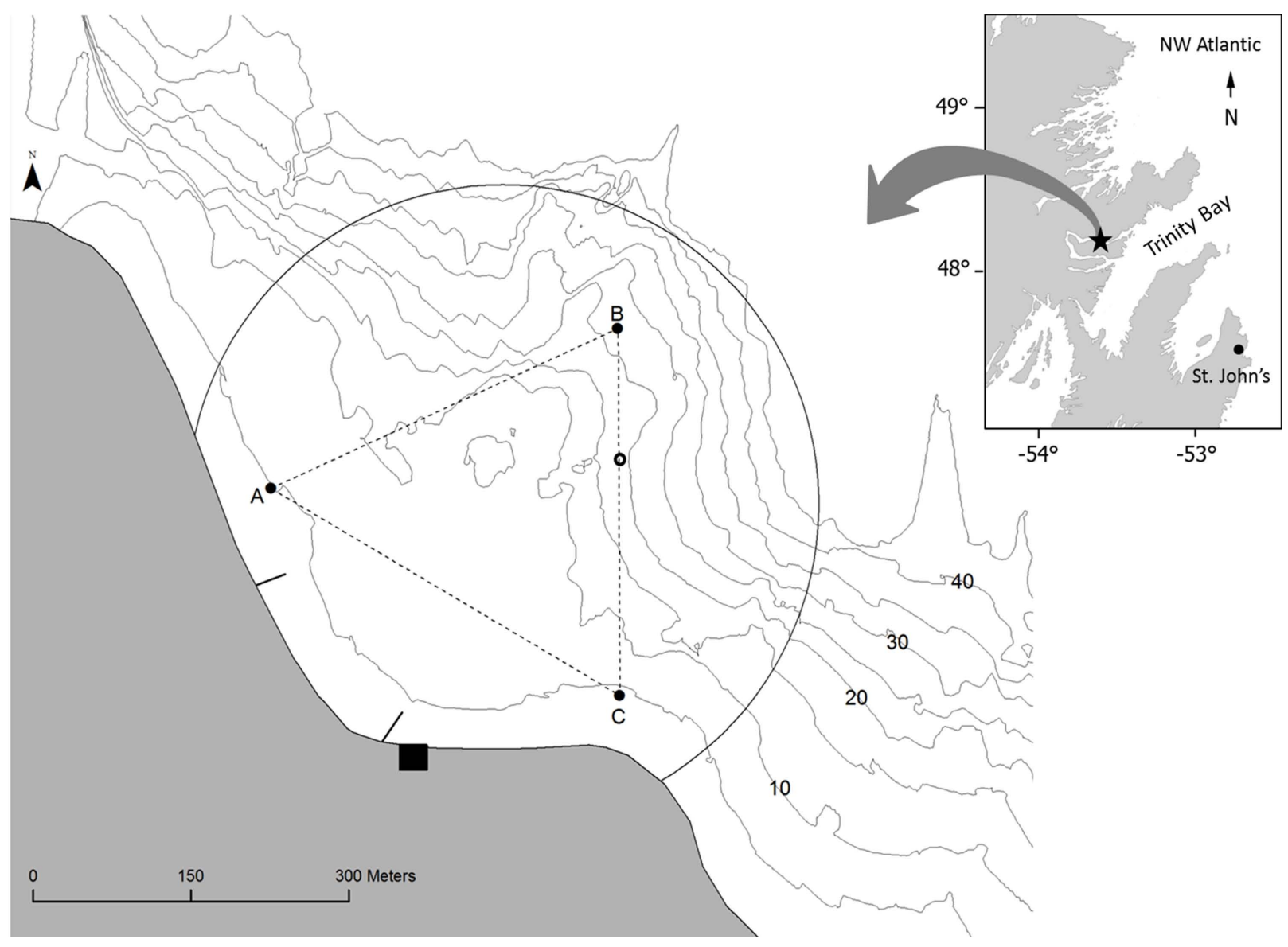

Fig. (1). Map of study area. Inset shows study site relative to the eastern portion of Newfoundland. Enlarged area shows position of hydrophone array $(\bullet-$ radio-acoustic buoys A-C), base station $(\bullet)$, position of temperature loggers $(0)$, wharves $(-)$, positional range (circular black line - $300 \mathrm{~m}$ radius from array centre) and depth contours from acoustic recordings from the present study.

structured rock formations to densely vegetated (Laminaria $s p$ ) areas. Juvenile G. ogac and G. morhua are known to cooccur in this area and were commonly encountered during previous unrelated studies (e.g., [21]). The hydrophone array of the acoustic positioning system used to monitor individuals covered an area approximately 5.7 ha while the detection range of the system encompassed roughly 25 ha (Fig. 1).

\section{Habitat Mapping}

A combination of acoustic remote sensing and underwater video were used to create a map of the study area. Repeated acoustic surveys were conducted over 2 days in July of 2009 using a calibrated [22] Biosonics DT-X digital echosounder system (Biosonics Inc., Seattle, WA, USA) with $120 \mathrm{kHz}$ single beam $\left(6^{\circ}\right)$ and $200 \mathrm{kHz}$ split-beam $\left(6.5^{\circ}\right)$ transducers, mounted in close proximity on the RV "Gecho" $(6 \mathrm{~m})$. The transducers transmitted $0.4 \mathrm{~ms}$ pulses alternately at the rate of 5 pulses $\mathrm{s}^{-1}$, with an internal digitizing depth increment of approximately $1.4 \mathrm{~cm}$. The vessel performed a series of overlapping transects spanning the detection range of the positioning system at a speed of 3-4 knots (Fig. 2). The vessel drew $<0.5 \mathrm{~m}$ of water and was able to survey very close to shore to water depths less than the beam forming range of the transducers (approximately $3 \mathrm{~m}$ ). Substrate composition was semi-quantitatively verified with video footage in situ using a submersible video camera (Sea-Drop
950, Sea Viewer Cameras, Inc., Tampa, FL) deployed from the vessel. Date/time stamps and GPS data enabled acoustic data and video to be matched closely. Substrate composition was verified at 125 locations (Fig. 2).

Acoustic data was analyzed and integrated using QTC IMPACT (acoustic seabed classification for echo sounders) (Quester Tangent Corporation, Saanichton, BC, CAN). This software system analyses return echoes from the seafloor and grouped them into classes based on similarities in vertical patterns and strengths of the backscatter. We used the software's automated clustering function to determine an optimal number of classes. We subsequently grouped several classes based on similar acoustic properties and video images to reduce the total number of substrate classes within the range $(8-12)$ usually produced with higher resolution sidescan acoustics (JT Anderson, DFO, ST. John's, NL, personal communication, 2012). Finally, derived classes were interpolated between tracks using the inverse distance weighting (IDW) method in ArcMap 9.3 (ESRI, Redlands, CA, USA). Although biotic habitat features (namely macrophyte distribution) may vary seasonally, we observed no notable changes in macrophyte distribution between years therefore the final map generated was assumed to be representative of the habitat in both years of the study. Substrate particle size was estimated by keeping the camera at a fixed distance $(\sim 1 \mathrm{~m})$ from the bottom to maintain a consistent 


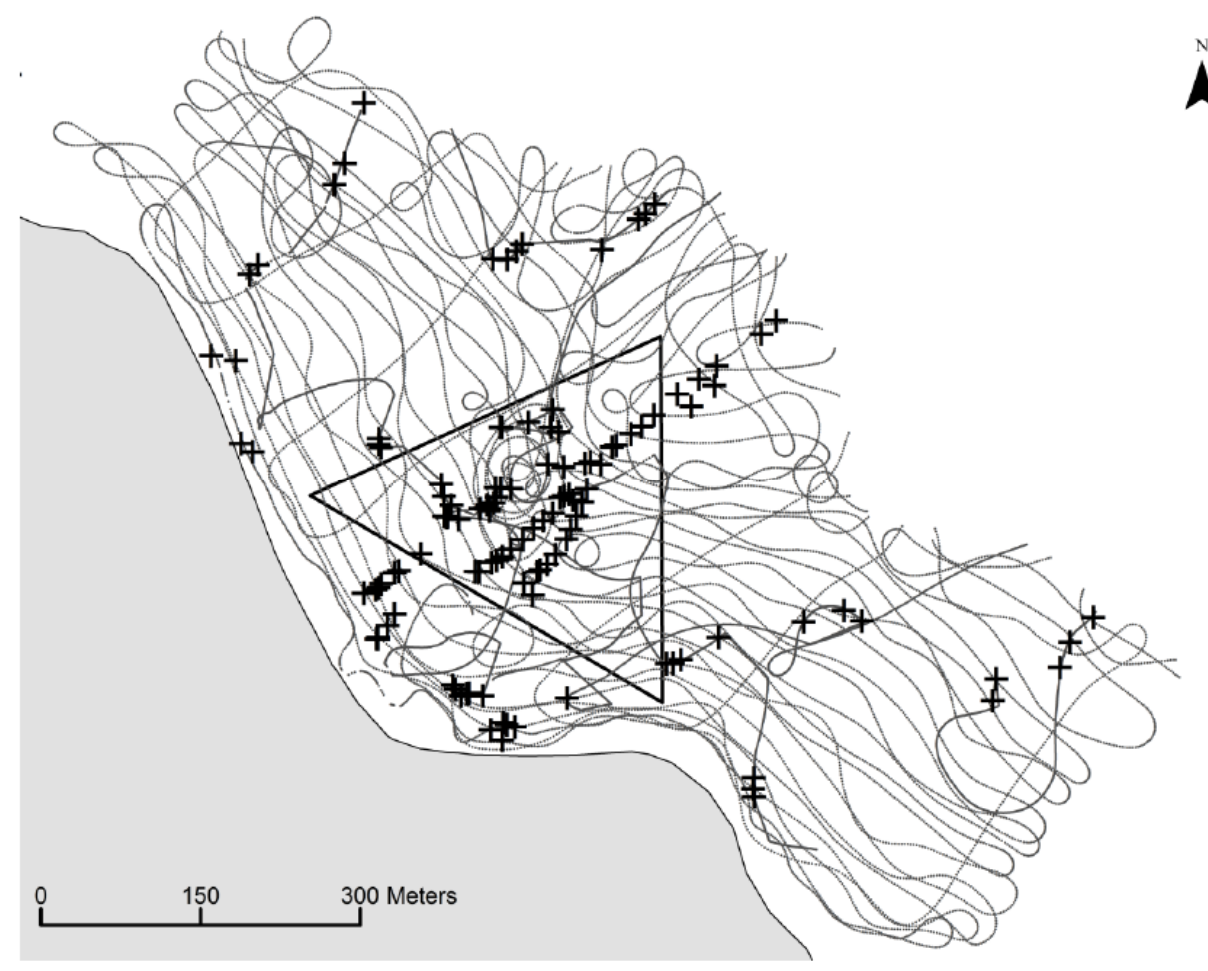

Fig. (2). Acoustic survey tracks (dotted lines) (15-17 Jul, 2009) and seabed video locations (+).

view of the field. As well, objects of known size (i.e., from anthropogenic sources) on the substrate provided an additional means to approximate particle size.

To generate a bathymetric profile of the study area, acoustic estimates of depth to the seafloor were edited in Echoview 4.8 (Myriax Pty Ltd., Hobart, Tasmania, AUS), then corrected for tidal amplitude and plotted on a georeferenced map of the study area and interpolated by inverse distance weighting (IDW) in ArcMap 9.3 (ESRI, Redlands, CA, USA). The slope tool in ArcMap was used to calculate the slope $\left({ }^{\circ}\right)$ of the seabed within the study area and create three classes of bathymetric relief: Low $\left(<5^{\circ}\right.$ slope $)$, moderate $\left(5-10^{\circ}\right.$ slope $)$, and high $\left(>10^{\circ}\right.$ slope $)$. Surface $(\sim 1 \mathrm{~m})$, mid-water $(\sim 10 \mathrm{~m})$ and bottom $(\sim 20 \mathrm{~m})$ water temperatures were recorded at 5 minute intervals at a fixed location within the study area (Fig. 1) using Minilog data loggers (VEMCO Division, AMIRIX Systems Inc., NS, CAN).

\section{Tagging and Tracking}

Juvenile ( $\sim 30-45 \mathrm{~cm}$ TL) Atlantic and Greenland cod were caught within the study area by angling using single, barbless hooks and selected for tagging to provide a comparable size range between species. Fish were placed in an anaesthetic solution of MS-222 and sea water $\left(\sim 0.1 \mathrm{gL}^{-1}\right)$ until equilibrium was lost. Fish were then measured and a continuous acoustic transmitter (VEMCO V9P-1H, 9 x $40 \mathrm{~mm}$, $5.2 \mathrm{~g}$ in air) equipped with a pressure sensor was implanted in the body cavity through a small $(\mathrm{ca} .1 \mathrm{~cm})$ incision made in the belly anterior to the vent and slightly offset from the mid-ventral line. A single suture was used to close the wound and fish were placed in fresh sea water to recover. Once recovered, fish were released at or near the point of capture. Tagged fish were tracked on a continuous basis us- ing an acoustic positioning system (VEMCO VRAP, Vemco, Bedford, NS, CAN) consisting of three fixed hydrophone buoys equipped with radio antennas arranged in a triangle over the study area (Fig. 1). Buoy hydrophones received acoustic pulses from transmitters and relayed the information via radio signal to a land-based station where the data was viewed and stored on computer disc. The exact position of each transmitter was triangulated autonomously by the system based on the time delay in pulses arriving at each buoy. Tags set at three different frequencies $(63,75$, and $81 \mathrm{kHz})$ transmitted every $15-35 \mathrm{~s}$. The system could potentially record an individual's position in 3 dimensions approximately once every $180 \mathrm{~s}$. The accuracy of the system was tested by mooring a stationary transmitter at a known location within the study area. Mean $( \pm \mathrm{SE})$ positional accuracy was $2.48 \mathrm{~m}$ $\pm 0.25 \mathrm{~m}$ inside the buoy array and $6.53 \pm 0.17 \mathrm{~m}$ outside the array and was similar to other studies [23-26]. To determine the acoustic range of the system, a single transmitter was lowered to a depth of $\sim 10 \mathrm{~m}$ from a research vessel at increasing $50 \mathrm{~m}$ intervals from the centre of the array. Range tests showed successful detections beyond $450 \mathrm{~m}$, however, a conservative $300 \mathrm{~m}$ effective detection range was used because positional accuracy is known to decrease with distance from the array (e.g., $[24,25,27])$. The accuracy of the pressure sensor within transmitters was tested by anchoring a stationary transmitter for an extended period of time during calm conditions and examining the statistical dispersion of depth measurements. Mean $( \pm$ SE) depth for a transmitter moored at approximately $12.5 \mathrm{~m}$ was $12.66 \pm 0.04 \mathrm{~m}$ $(\mathrm{n}=295)$.

\section{Habitat Associations}

Tracking data obtained within the first 24 hours after tagging and release were omitted from analyses to remove any 
potential effect of surgical implantation on fish behaviour (see [28]). Past $24 \mathrm{~h}$ post-released there was no indication of lethargic behaviour that differed from the remainder of the study period. The remaining positional fixes were plotted on the geo-referenced habitat map of the study area and a small number $(<1 \%)$ of invalid fixes (i.e., detections on land, detections from unrecognized transmitter IDs, etc.) were removed. The proportion of fixes occurring within each habitat type was determined using Hawth's Analysis Tools for ArcMap [29]. To test whether each species used habitats in proportion to their availability or were selecting for certain habitats, log-likelihood chi-square tests with fish as sampling units were used $[30,31]$. The first test determined whether selection for specific habitats was occurring while the second determined whether individuals were utilizing habitats similarly. The difference between the two chi-squares defined whether on average, habitat types were used in proportion to their availability. Where non-proportional use was determined, habitat preference and avoidance was assessed using selection ratios defined as habitat utilization (proportion of fixes in a certain habitat) divided by habitat availability (proportion that particular habitat type available within the $300 \mathrm{~m}$ detection range). Bonferroni-adjusted $95 \%$ confidence intervals were calculated for each selection ratio and intervals encompassing the value 1 indicated proportional habitat use based on availability. Intervals where the lower limit $>1$ indicated selection for a given habitat while those where the upper limit $<1$ indicated avoidance [30]. Selection ratios and confidence intervals were calculated for total, day and night periods. To quantify overlap in habitat use between species the proportional use of each habitat class for each species was determined and compared using the following equations from 1) Pianka [1]: $O=\sum_{i}^{n} p_{i j} p_{i k} / \sqrt{\sum_{i}^{n} p_{i j}{ }^{2} \sum_{i}^{n} p_{i k}{ }^{2}}$, and 2) Schoener [32]: $O=1-$ $0.5\left(\sum\left|p_{i j}-p_{i k}\right|\right)$, where $p_{i j}$ and $p_{i k}$ represent the proportional use of habitat class $i$ by species $j$ and $k$, respectively. Index values ranged from 0 (no overlap) to 1 (complete overlap) with values $\geq 0.6$ generally considered to be biologically significant [33].

\section{Depth Distribution}

To examine the vertical distribution of tagged individuals relative to bottom depth, we integrated bathymetry and fish depth data based on spatial location then subtracted fish depth from bottom depth to obtain a measure of altitude. Welch's t-tests were used to test for differences in depth and altitude between species for total, day and night periods defined as the time between sunrise and sunset and sunset and sunrise, respectively. F-tests were used to test for differences in variances in depth and altitude between species while regressions were used to test whether fish size was related to depth and altitude.

\section{RESULTS}

Twenty fish (10 G. morhua and $10 \mathrm{G.ogac})$ were tracked continuously for periods up to 23 days resulting in $>18700$ detections with the VRAP system between 24 June and 17 July, 2009 and 7-28 July, 2010 (Table 1). All fish survived the implantation and were detected with the VRAP system except for fish 21 (G. ogac, $49.0 \mathrm{~cm})$ which left the study area immediately after release and was detected manually 13 days later, approximately $4 \mathrm{~km}$ from the release point. Mean ( $\pm \mathrm{SE}$ ) fish length did not differ between years (ANOVAs, $\mathrm{p}>0.05)$, therefore telemetry data for both years were pooled by species.

\section{Habitat Mapping}

Seafloor substrate identified by video footage varied from solid rock and boulders to fine gravel and sand (Fig. 3). Cabbage kelp (Laminaria longicruris) was the dominant macrophyte and was abundant in areas $<10 \mathrm{~m}$ deep, often creating narrow, maze-like pathways between the vegetation (Fig. 3a). Red seaweeds (rhodoliths, Porphyra sp.) and brown algae (Desmarestia viridis) were also present (Fig. 3b). Kelp patches were generally dense, often prohibiting the visual identification of substrate particles. Closer to the center of the array, a shallow rocky outcropping comprised mainly of solid rock (Fig. 3c) and boulders was evident in both video and acoustic data. Deeper areas $(>30 \mathrm{~m})$ were generally characterized by little or no vegetation and fine gravel substrate (Fig. 3d). Based on dominant substrate particle size and degree of macrophyte coverage determined from video footage, the unsupervised seabed classification derived by the QTC software was selected to represent: 1) fine gravel $/ \mathrm{sand}(<0.3 \mathrm{~cm}$ diameter $), 2)$ fine gravel $/ \mathrm{sand}$ with moderate $(25-50 \%)$ coverage, 3$)$ coarse gravel (0.3-10 $\mathrm{cm})$ with moderate coverage, 4) coarse gravel with dense (> 50\%) coverage, 5) small cobble $(10-15 \mathrm{~cm})$ with dense coverage, 6) large cobble $(15-20 \mathrm{~cm})$ with dense coverage, 7$)$ boulders $(>20 \mathrm{~cm})$ with moderate coverage and 8$)$ solid rock (Fig. 4).

\section{Habitat Utilization}

Both species showed strong selection for certain types of substrate and bathymetric relief (Log likelihood chi-square tests; Table 2). Over the entire diel cycle, both species avoided fine gravel/sand substrates with little vegetation and selected for small and large cobble and boulder substrates with moderate or dense vegetation (Fig. 5a). G. ogac also avoided coarse gravel with moderate vegetation whereas G. morhua neither selected nor avoided this substrate (Fig. 5a). In daytime, both species avoided fine gravel/sand substrates with little vegetation and selecting for cobble and boulders with moderate or dense vegetation (Fig. 5b). In addition, G. morhua selected for coarse gravel with moderate vegetation and both species avoided areas with boulders and no vegetation (Fig. 5b). At night, as in daytime, both species avoided fine gravel/sand substrates with little vegetation and coarse gravel with moderate vegetation and selected for small and large cobble with moderate and dense vegetation (Fig. 5c). Bedrock with no vegetation was also avoided at night by both species (Fig. 5c). Preference and avoidance for the same habitat was generally stronger in G. ogac (Fig. 5). Both species showed strong selection for low $\left(0-5^{\circ}\right.$ slope $)$ relief areas and avoidance of moderate (5-10 $0^{\circ}$ slope) and high $\left(>10^{\circ}\right.$ slope) relief areas both day and night (Fig. 6). Selection for and avoidance of was generally stronger for G. ogac except for at night when selection ratios were similar (Fig. 6). Both overlap indices showed high overlap for substrate (Pianka: $O=0.98$; Schoener: $O=0.87$ ) and slope (Pianka: $O=0.98$; Schoener: $O=0.88$ ). 
Table 1. Data summary for all fish monitored in Smith Sound, 2009-2010 (*-omitted from analyses).

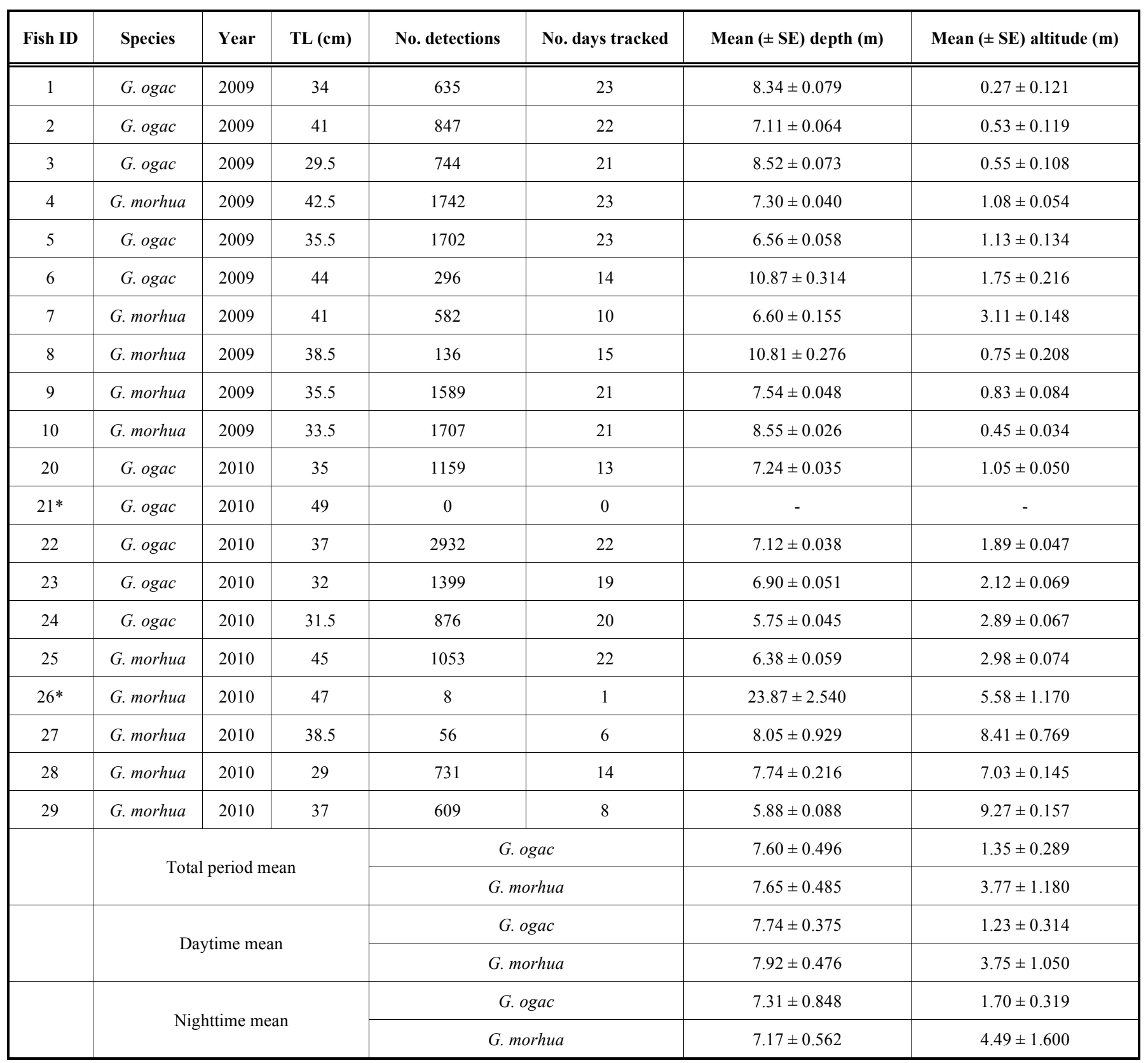

\section{Depth Distribution}

Mean depth and altitude for each fish as well as for each species by diel period are shown in (Table 1). Overall, $78 \%$ of detections for $G$. morhua were between 5 and $10 \mathrm{~m}$, $13.6 \%$ were at depths less than $5 \mathrm{~m}$ and $8.2 \%$ were at depths greater than $10 \mathrm{~m}$. For G. ogac, $80.2 \%$ of detections were between 5 and $10 \mathrm{~m}, 14.8 \%$ were at depths less than $5 \mathrm{~m}$ and $5 \%$ were at depths greater than $10 \mathrm{~m}$. The maximum depths recorded were $28.5 \mathrm{~m}$ (fish 6) and $36.8 \mathrm{~m}$ (fish 28) for G. ogac and G. morhua, respectively. Mean depth occupied did not differ between species for total, daytime or nighttime periods (Welch's t-tests, $\mathrm{p}>0.05$ ). G. ogac was generally distributed closer to the bottom than $G$. morhua for all periods, however only mean daytime altitude was significantly different between species (Welch's t-test, $\mathrm{t}=-2.30, \mathrm{p}=$
0.047) (Fig. 7). Variances for depth did not differ between species $\left(\mathrm{F}\right.$-test, $\left.\mathrm{F}_{(9,9)}=1.04, \mathrm{p}>0.05\right)$. G. morhua had a significantly greater variance in altitude than $G$. ogac (F-test, $\mathrm{F}_{(9,9)}=16.7, \mathrm{p}<0.01$ ) (Fig. 7). A significant relationship between body size (TL) and maximum depth was observed for $G$. ogac $\left(\mathrm{r}^{2}=55.1, \mathrm{p}=0.022, \mathrm{n}=9\right)$ but not $G$. morhua $(\mathrm{p}=0.207)$. Body size was not significantly related to mean depth or altitude for either species $(p>0.05)$.

\section{DISCUSSION AND CONCLUSION}

Results from the present study suggest that juvenile G. ogac and G. morhua in coastal Newfoundland occupied the same habitats and were distributed at similar depths of $<10 \mathrm{~m}$. Nevertheless, altitudes generally differed with G. morhua on average located further from the seafloor and 

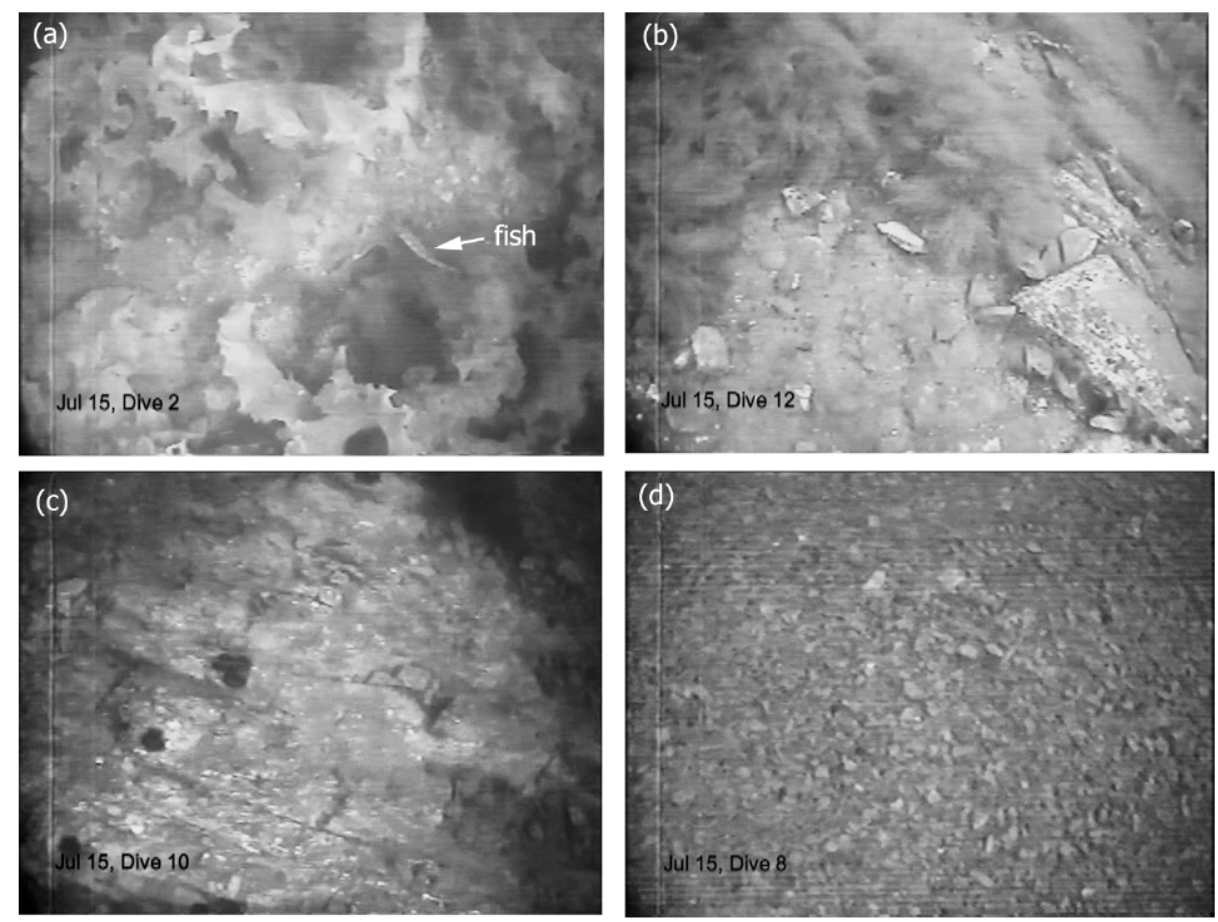

Fig. (3). Example images from video ground-truthing observations of the seafloor: (a) coarse gravel with $>50 \%$ vegetation (Laminaria $s p$ ) coverage (with unknown fish), (b) large cobble and boulders with 50\% vegetation (Desmarestia viridis), (c) solid rock, and (d) fine gravel.

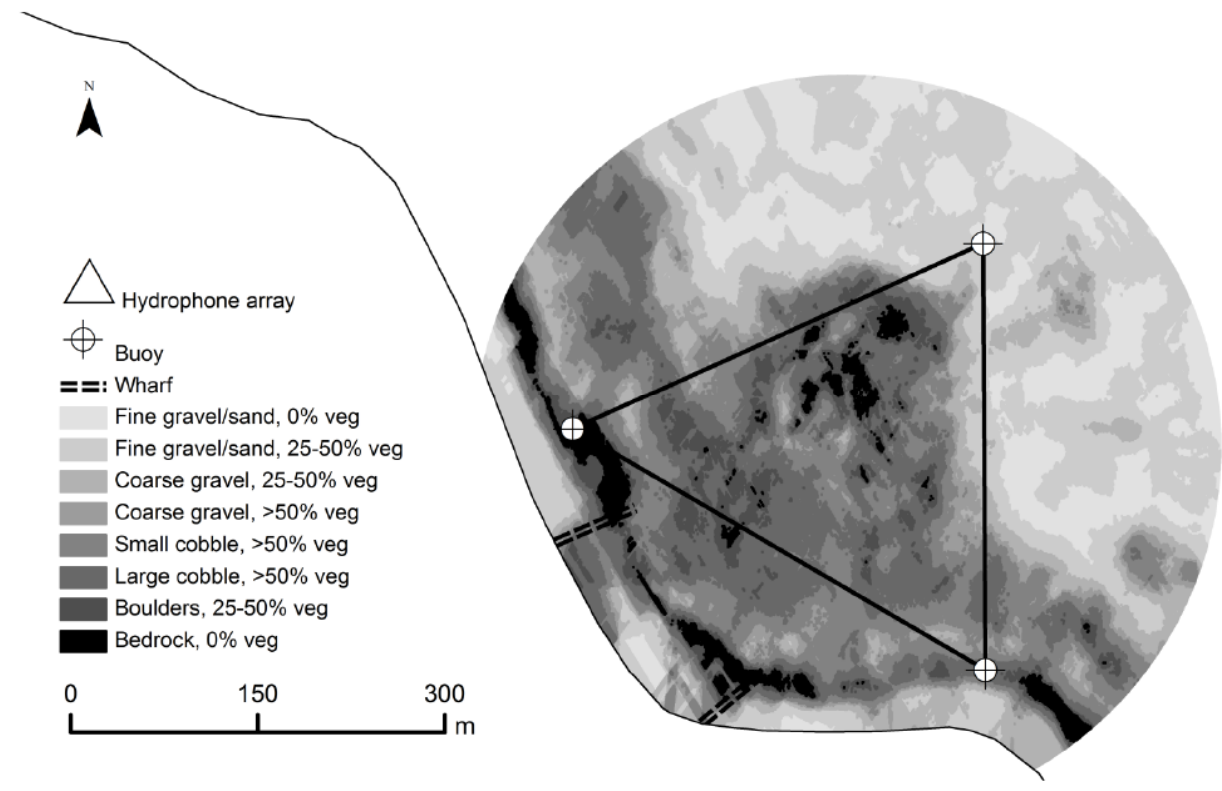

Fig. (4). Results of the seabed substrate unsupervised classification.

showing more variation in altitude. Both species selected for moderately to densely covered areas with large substrate particles and (cobble and boulders) and low bathymetric relief areas, while avoiding substrates having little or no vegetation and fine substrate particles and moderate to high bathymetric relief.

\section{Habitat Use}

A preference for areas with coarse substrates and dense aquatic vegetation habitat by both species was likely related to predator avoidance and/or foraging. Several single-species studies have shown that younger juvenile G. morhua (age $0-1+$ ) selected coarse substrates and vegetated areas to reduce risk of predation (e.g., [12, 34-36]). Other studies from coastal Newfoundland have shown that older (age 2-4) juvenile $G$. morhua were typically associated with macroalgae and/or coarse substrates [11, 13-16]. Large $(>60 \mathrm{~cm})$ cod are known to prey on smaller conspecifics as well as $G$. ogac $[8,37,38]$, and were observed acoustically and caught by angling in close proximity to the study area. Hence, selection by both young gadids for complex substrates is consistent with an anti-predator strategy. 
Table 2. Results of log-likelihood chi-square tests comparing habitat use and proportion of availability for tagged $G$. ogac and G. morhua. The results of the first tests indicate that both species were selective in the types of habitat while the second tests establish that fish used habitats very differently from one another. The difference between the chi-square tests demonstrates strong selection for certain habitat types within species.

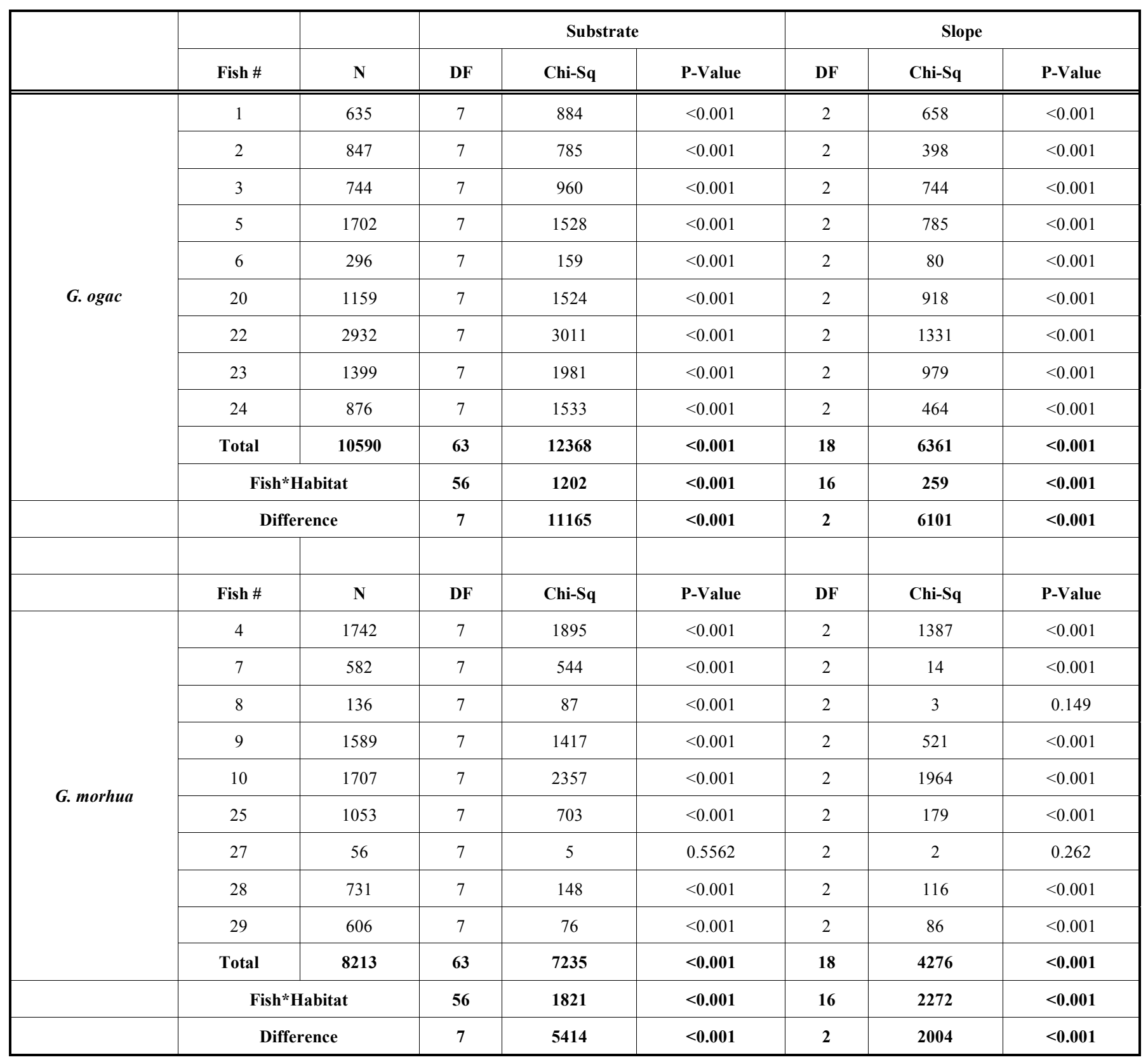

Our results are inconsistent with single-species studies that reported older juvenile G. morhua were not associated with macroalgae [13,17] or were typically observed over sand [18]. Gregory and Anderson [13] speculated that the lack of association with macroalgae in their study was due to seasonal differences in juvenile and adult (predator) distribution and suggested older juveniles may only associate with macroalgae in summer and fall. In our summertime study, juveniles of both species showed a strong selection for coarse substrates and areas with dense algae. Predator (large cod) abundance varies seasonally in Smith Sound [39] and more generally in coastal waters of the northeast coast of Newfoundland. Hence, if predator avoidance is the key fac- tor in habitat selection by juvenile gadids, then their location and spatial overlap is likely to vary seasonally. Further studies are required to address this hypothesis.

It is also possible that juvenile gadids prefer complex and macrophyte habitats because of the availability of food (e.g., 20 for G. ogac). Dietary overlap between juvenile G. morhua and G. ogac does occur, with both species feeding on organisms typically associated with inshore macroalgae beds such as polychaetes and benthic fish (e.g., shannys; Stichaeidae) $[5,40]$. Nevertheless, there are key differences is the diets of these gadids $[8,37]$ which might be expected to lead to different habitat use patterns if food is the key factor. The more 
benthic habits of $G$. ogac may be related to the more benthic diet of this species in comparison to the more pelagic behaviour of $G$. morhua.

(a)

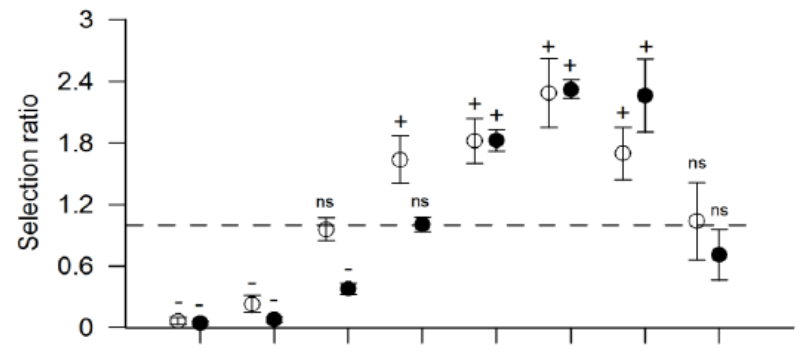

(b)

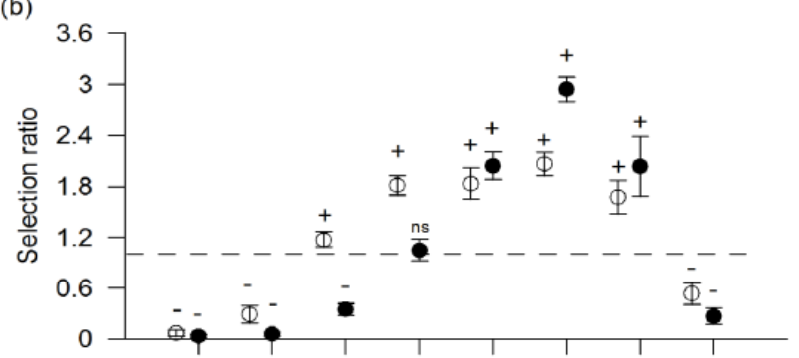

(c)

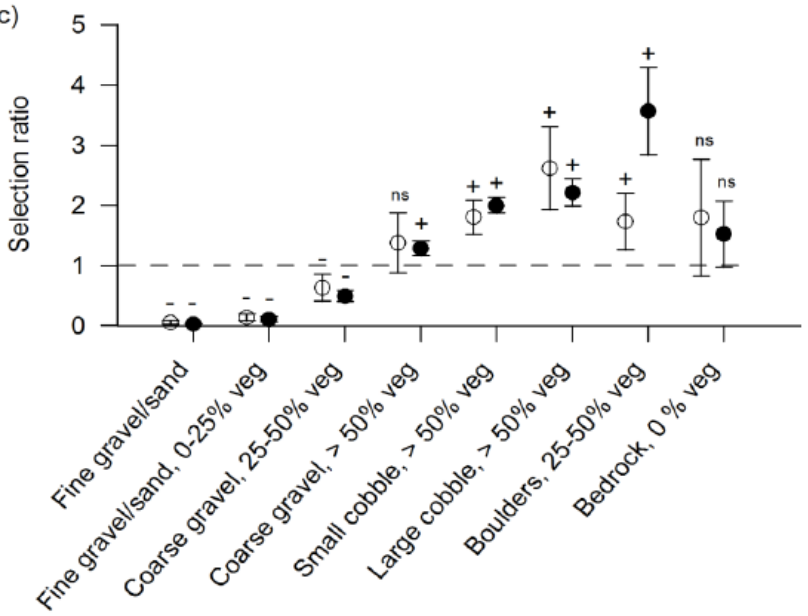

Fig. (5). Selection ratios with Bonferroni-adjusted $90 \%$ CIs by substrate class for G. ogac (•) and G. morhua (०) calculated for (a) total, (b) daytime and (c) nighttime periods. In each panel, the horizontal dashed line indicates an index value of 1 (proportional use of habitat). Symbols indicate selection for $(+)$, proportional use (ns) and avoidance (-) of habitat types.

The strong association with areas of low bathymetric relief by both species was not expected $a$ priori and conflicts with single-species studies that have reported that older juvenile $G$. morhua select for areas of medium and high relief in coastal Newfoundland $[13,16]$. However, in both the latter studies, coarse substrate (cobble, rock/boulder) and high bathymetric relief were generally found together and whether juveniles were selecting for habitat based on substrate type or vertical relief remained unclear. Considering all the evidences, we suggest that juvenile habitat of both gadids in summer is largely determined by substrate type and macrophyte coverage and not bathymetric relief, although combinations of these features may be relevant [13]. (a)

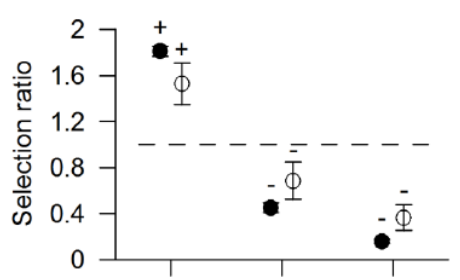

(b)

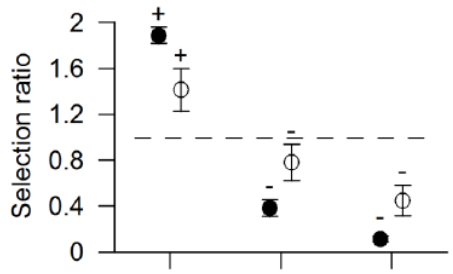

(c)

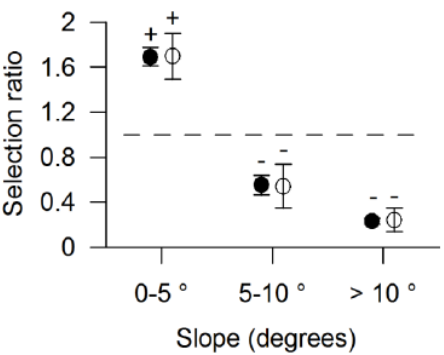

Fig. (6). Selection ratios with Bonferroni-adjusted 90\% CIs by bathymetric relief (slope) class for G. ogac (•) and G. morhua (०) calculated for (a) total, (b) daytime and (c) nighttime periods. In each panel, the horizontal dashed line indicates an index value of 1 (proportional use of habitat. Symbols indicate selection for $(+)$, proportional use (ns) and avoidance (-) of habitat types.
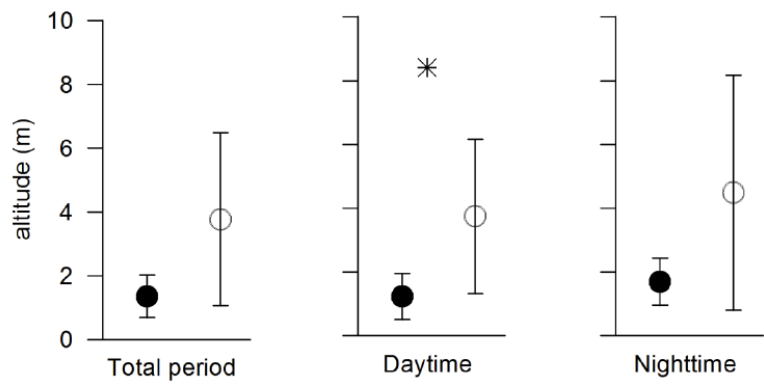

Fig. (7). Plots of mean altitude ( $\pm \mathrm{CI})$ for $G$. ogac $(\bullet)$ and $G$. morhua (०) for total, daytime and nighttime periods. Asterisk indicates significant difference in mean altitudes (Welch's t-test, $\mathrm{p}<0.05$ ).

\section{Vertical Distribution}

Whereas many habitat preferences were shared by these co-occurring juvenile gadids, the most apparent difference was a propensity for G. morhua to be distributed higher in the water column and display greater variation in altitude as compared to G. ogac. Young G. morhua appear to adapt to a more pelagic existence while $G$. ogac is primarily demersal. We further suggest that even a small segregation along the vertical habitat dimension may assist coexistence between these two species and that this pattern is likely a component of differences in foraging behaviour. G. morhua tends to 
have a higher proportion of pelagic food items $[8,37]$ and a more pelagic stable isotope signature than does G. ogac [8].

In the present study, both species maintained similar depth and altitude distributions across the diel cycle. These results differ from reports for G. morhua in summer by Clark and Green [18] in which older juveniles rested in cooler, deep $(>30 \mathrm{~m})$ water during the day and moved to warmer, shallower water at night. Differences in water temperature regimes might explain these differences. In the present study, both species occupied deeper water and were positioned closer to the bottom in 2009 when bottom temperatures were considerably warmer than in 2010 (Fig. 8). Temperature is well known to influence inshore cod distribution (e.g., [41]) and it is likely that this factor will influence selection for habitat as well as feeding opportunities.
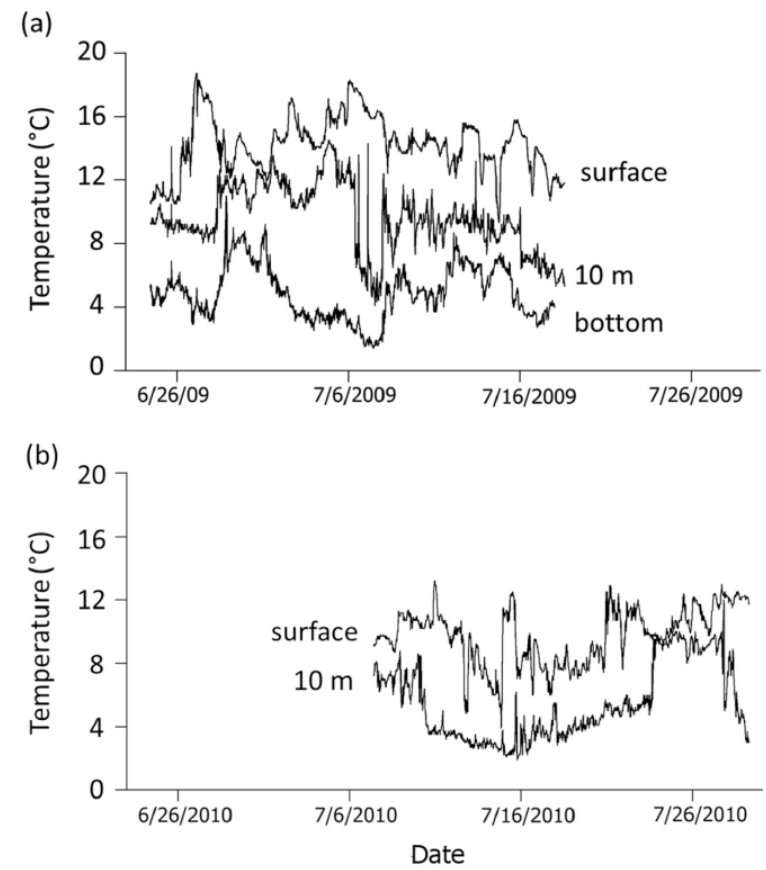

Fig. (8). Water temperature data at the study site in (a) 2009 and (b) 2010. (Note - no data for bottom temperatures in 2010).

In conclusion, our results suggest the co-occurring G. morhua and G. ogac are partitioning habitat by having different vertical distributions over the same grounds. These results are consistent with other studies with closely related fish species (e.g., [42-45]). We suggest that this segregation is largely the modus operandi of differences in foraging strategies and prey selection.

\section{CONFLICT OF INTEREST}

The authors confirm that this article content has no conflicts of interest.

\section{ACKNOWLEDGEMENTS}

We thank E. Stern, D. Pike, and T. Clenche for support in the field, P. Gagnon for help with kelp identification, and J. Anderson for assistance with seabed mapping. This work was funded by grants from the Newfoundland and Labrador Department of Fisheries and Aquaculture and the Natural
Sciences and Engineering Research Council of Canada, and from the Newfoundland and Labrador Institute for Biodiversity, Ecosystem Science and Sustainability.

\section{REFERENCES}

[1] Pianka ER. The structure of lizard communities. Annu Rev Ecol Evol Syst 1973; 4: 53-74.

[2] Schoener TW. Resource partitioning in ecological communities. Science 1974; 185: 27-39.

[3] Ross ST. Resource partitioning in fish assemblages: a review of field studies. Copeia 1986; 1986(2): 352-88.

[4] Morris DW. Toward an ecological synthesis: a case for habitat selection. Oecologia 2003; 136: 1-13.

[5] Scott WB, Scott MG. Atlantic fishes of Canada. Toronto, Ontario; University of Toronto Press, Scholarly Publishing Division, 1988.

[6] Rose GA. Cod: the ecological history of the north Atlantic fisheries. St. John's, Newfoundland and Labrador; Breakwater 2007.

[7] Cohen DM, Inada T, Iwamoto T, Scialabba N. FAO Species Catalogue. Volume 10. Gadiform fishes of the world (Order Gadiformes). An annotated and illustrated catalogue of cods, hakes, grenadiers and other gadiform fishes known to date. Rome, Italy; Food and Agricutlure Organization of the United Nations, 1990.

[8] Knickle DC, Rose GA. Dietary niche partitioning in sympatric gadid species in coastal Newfoundland: evidence from stomachs and $\mathrm{C}-\mathrm{N}$ isotopes. Environ Biol Fish 2013; doi:10.1007/s10641013-0156-0.

[9] Knickle DC, Rose GA. Spatial-temporal niche partitioning in Atlantic cod (Gadus morhua) and Greenland cod (Gadus ogac) in coastal Newfoundland. CJ Fish Biol. In press.

[10] Kramer DL, Rangeley RW, Chapman L. Habitat selection: patterns of spatial distribution from behavioural decisions. In: Godin J-GJ, Ed. Behavioural ecology of teleost fishes. Oxford University Press, New York 1997; pp. 37-80.

[11] Keats DW, Steele DH, South GR. The role of fleshy macroalgae in the ecology of juvenile cod (Gadus morhua L.) in inshore waters off eastern Newfoundland. Can J Zool 1987; 65: 49-53.

[12] Gotceitas V, Fraser S, Brown JA. Use of eelgrass beds (Zostera marina) by juvenile Atlantic cod (Gadus morhua). Can J Fish Aquat Sci 1997; 54: 1306-19.

[13] Gregory RS, Anderson JT. Substrate selection and use of protective cover by juvenile Atlantic cod Gadus morhua in inshore waters of Newfoundland. Mar Ecol Prog Ser 1997; 146: 9-20.

[14] Cote D, Moulton S, Scruton DA, McKinley RS. Microhabitat use of juvenile Atlantic cod in a coastal area of Bonavista Bay, Newfoundland. Trans Amer Fish Soc 2001; 130: 1217-23.

[15] Cote D, Ollerhead LMN, Scruton DA, McKinley RS. Microhabitat use of juvenile Atlantic cod in a coastal area of Newfoundland determined by 2D telemetry. Mar Ecol Prog Ser 2003; 265: 227-34.

[16] Cote D, Moulton S, Frampton PCB, Scruton DA, McKinley RS. Habitat use and early winter movements by juvenile Atlantic cod in a coastal area of Newfoundland. J Fish Biol 2004; 64: 665-79.

[17] Keats DW. A nocturnal inshore movement of juvenile cod Gadus morhua L. in eastern Newfoundland. J Exp Mar Biol Ecol 1990; 139: 167-73.

[18] Clark DS, Green GM. Activity and movement patterns of juvenile Atlantic cod, Gadus morhua, in Conception Bay, Newfoundland, as determined by sonic telemetry. Can J Zool 1990; 68: 1434-42.

[19] Mikhail MY, Welch HE. Biology of Greenland cod, Gadus ogac, at Saqvaqjuac, northwest coast of Hudson Bay. Env Biol Fish 1989; 26: 49-62.

[20] Morin B, Hudon C, Whoriskey F. Seasonal distribution, abundance, and life-history traits of Greenland cod, Gadus ogac, at Wemindji, eastern James Bay. Can J Zool 1991; 69: 3061-70.

[21] Knickle DC, Rose GA. Seasonal spawning and wind-regulated retention-dispersal of early life stage Atlantic cod (Gadus morhua) in a Newfoundland fjord. Fish Oceanogr 2010; 19(5): 397-411.

[22] Foote KG, Knudsen HP, Vestnes G, MacLennan DN, Simmonds EJ. Calibration of acoustic instruments for fish density estimation. ICES Cooperative Research Report 114, 1987.

[23] Sauer WHH, Roberts MJ, Lipinsk MR, et al. Choreography of the squid's "nuptial dance". Biol Bull 1997; 192: 203-7.

[24] O'Dor RK, Andrade Y, Webber DM, et al. Applications and performance of Radio-Acoustic Positioning and Telemetry (RAPT) systems. Hydrobiologia 1998; 371/372: 1-8. 
[25] Klimley AP, Le Boeuf BJ, Cantara KM, Richert JE, Davis SF, Van Sommeran S. Radio-acoustic positioning: a tool for studying sitespecific behavior of the white shark and large marine vertebrates. Mar Biol 2001; 138: 429-46

[26] Barnett A, Abrantes KG, Stevens JD, Bruce BD, Semmens JM. Fine-Scale movements of the broadnose sevengill shark and its main prey, the gummy shark. PLoS ONE 2010; 5(12): 1-10 e15464.

[27] Espeland SH, Gundersen AF, Olsen EM, Knutsen H, Gjøsæter J, Stenseth NC. Home range and elevated egg densities within an inshore spawning ground of coastal cod. ICES J Mar Sci 2007; 64: 920-8.

[28] Cote D, Scruton DA, Cole L, McKinley RS. Swimming performance and growth rates of juvenile Atlantic cod intraperitoneally implanted with dummy transmitters. N Amer J Fish Manage 1999; 19: 1137-41.

[29] Beyer HL. Hawth's Analysis Tools for ArcGIS. 2004 Available from: Document1http://www.spatialecology.com/htools

[30] Manly BF, McDonald L, Thomas D, McDonald T, Erickson W. Resource selection by animals: statistical design and analysis for field studies. $2^{\text {nd }}$ ed. Boston, Massachusetts; Kluwer Academic 2002.

[31] Rogers KB, White GC. Analysis of movement and habitat use from telemetry data. In: Guy CS, Brown ML, Eds. Analysis and interpretation of freshwater fisheries data. American Fisheries Society, Bethesda, Maryland 2007; pp. 625-76.

[32] Schoener TW1970. Non-synchronous spatial overlap of lizards in patchy habitats. Ecology 1970; 51: 408-18.

[33] Wallace RK Jr. An assessment of diet-overlap indexes. Trans Amer Fish Soc 1981; 1(10): 72-6.

[34] Gotceitas V, Brown JA. Substrate selection by juvenile Atlantic cod (Gadus morhua): effects of predation risk. Oecologia 1993; 93: 31-7.

[35] Gotceitas V, Fraser S, Brown JA. Habitat use by juvenile Atlantic cod (Gadus morhua) in the presence of an actively foraging and non-foraging predator. Mar Biol 1995; 123: 421-30.
[36] Linehan JE, Gregory RS, Schneider DC. Predation risk of age-0 cod (Gadus) relative to depth and substrate in coastal waters. J Exp Mar Biol Ecol 2001; 263: 25-44.

[37] Chaput GJ. The feeding of Atlantic cod (Gadus morhua) and rock cod (Gadus ogac) from inshore Labrador, summer. OLABS (Offshore Labrador Biological Studies) Program Report, submitted to Petro-Canada Explorations Ltd., St. John's, Newfoundland and Labrador 1981.

[38] Nielsen JR, Andersen M. Feeding habits and density patterns of Greenland cod, Gadus ogac (Richardson 1836), at West Greenland compared to those of the coexisting Atlantic cod, Gadus morhua L. J Northw Atl Fish Sci 2001; 29: 1-22.

[39] Rose GA. Monitoring coastal northern cod: towards an optimal survey of Smith Sound, Newfoundland. ICES J Mar Sci 2003; 60(3): 453-62.

[40] Christian JR, Grant CGJ, Meade JD, Noble LD. Habitat requirements and life history characteristics of selected marine invertebrate species occurring in the Newfoundland and Labrador region. Canadian Manuscript Report of Fisheries and Aquatic Science $2925,2010$.

[41] Rose GA, Leggett WC. Atmosphere-ocean coupling and Atlantic cod migrations: effects of windforced variations in sea temperatures and currents on nearshore distributions and catch rates of Gadus morhua. Can J Fish Aquat Sci 1988; 45: 1234-43.

[42] Baker JA, Ross ST. Spatial and temporal resource utilization by southeastern cyprinids. Copeia 1981; 1981(1): 178-89.

[43] Shpigel M, Fishelson L. Habitat partitioning between species of the genus Cephalopholis (Pisces, Serranidae) across the fringing reef of the Gulf of Aqaba (Red Sea). Mar Ecol Prog Ser 1989; 58: $17-22$.

[44] Goldschmidt T, Witte F, de Visser J. Ecological segregation in zooplanktivorous haplochromine species (Pisces: Cichlidae) from Lake Victoria. OIKOS 1990; 58: 343-55.

[45] Albertson RC. Morphological divergence predicts habitat partitioning in a Lake Malawi cichlid species complex. Copeia 2008; 2008(3): 689-98

(C) Knickle and Rose; Licensee Bentham Open

This is an open access article licensed under the terms of the Creative Commons Attribution Non-Commercial License (http://creativecommons.org/licenses/by-nc/3.0/) which permits unrestricted, non-commercial use, distribution and reproduction in any medium, provided the work is properly cited. 